\title{
Systemic Illiquidity in the Federal Funds Market
}

\author{
By Adam B. Ashcraft and Darrell Duffie*
}

This paper shows how the intraday allocation and pricing of overnight loans of federal funds reflect the decentralized interbank market in which these loans are traded. A would-be borrower or lender typically finds a counterparty institution by direct bilateral contact. Once in contact, the two counterparties to a potential trade negotiate terms that reflect their incentives for borrowing or lending, as well as the attractiveness of their respective options to forego a trade and to continue "shopping around." This over-the-counter (OTC) pricing and allocation mechanism is quite distinct from that of most centralized markets, such as an electronic limit order book market in which every order is anonymously exposed to every other order with a centralized order-crossing algorithm.

While there is a significant body of research on the microstructure of specialist and limit order book markets, most OTC markets do not have comprehensive transaction-level data available for analysis. The federal funds market is a rare exception. We go beyond a previous study of the microstructure of the federal funds market (Craig H. Furfine 1999) by modeling how the likelihood of matching a particular borrower with a particular lender, as well as the interest rate that they negotiate, depend on their respective incentives to add or reduce balances and their ability to conduct further trading with other counterparties (proxied by the level of their past trading volumes). Our results are consistent with the thrust of search-based OTC financial

\footnotetext{
* Ashcraft: Banking Studies, Federal Reserve Bank of New York, 33 Liberty Street, NY, NY 10045 (e-mail: adam. ashcraft@ny.frb.org); Duffie: Graduate School of Business, Stanford University, 518 Memorial Way, Stanford, CA 94395-5015 (e-mail: duffie_darrell@gsb.stanford.edu). We are grateful for support and data from the Federal Reserve Bank of New York and for comments from Guillaume Plantin, Jamie McAndrews, Craig Furfine, Michael Fleming, and anonymous federal funds traders. We also have benefited from comments by Andrew Metrick, Jeremy Stein, Ken French, Larry Harris, Owen Lamont, John Taylor, and Randy Westerfield. The views expressed here are not necessarily those of the Federal Reserve Bank of New York or the Federal Reserve System.
}

market theory (see, for example, Duffie, Nicolae Gârleanu, and Lasse Heje Pedersen 2005; Ricardo Lagos 2005; and Dimitri Vayanos and PierreOlivier Weill 2005).

The rate that a borrower or lender bank negotiates on a loan is less attractive than current average rates negotiated in the market if the bank has more to gain from trade than its counterparty, and if the bank is less active in the market, after controlling for prior trading relationships. We offer alternative search-based explanations, going beyond credit risk variation.

More generally, we show how the likelihood that some bank $i$ borrows from some other bank $j$ during a particular minute $t$ of a business day, and how the interest rate negotiated on the loan, depend on: the prior trading relationship between these two banks; the extent to which their balances at the beginning of minute $t$ are above or below their normal respective balances for that time of day, their overall levels of trading activities, the amount of time left until their end-of-day balances are monitored for reserverequirement purposes, and the volatility of the federal funds rate in the trailing 30 minutes.

\section{The Federal Funds Market}

A federal funds transaction is executed with an electronic request made by a financial institution to the Federal Reserve Banks ("the Fed") via its Fedwire Funds Service, to debit its federal funds account by a stipulated amount in favor of the account of another financial institution. Such a "send" transaction could occur for many purposes, for example, to fund or repay a loan of federal funds or as settlement of a trade for other assets. The normal terms of a federal funds loan are the amount and interest rate quoted on a simple overnight money market (actual-360) basis. Loans are repaid by 6:30 P.M. Eastern time on the next business day. For example, a loan of $\$ 100$ million at a rate of 7.20 percent on a Tuesday would be executed with a send by the lender to the borrower of $\$ 100$ million on Tuesday and a send by the borrower to the lender of $100(1+0.072 / 360)=100.02$ million 
on Wednesday. Federal funds loans are not collateralized and therefore expose the lending institution to the risk of default by the borrowing institution. Credit risk could be partly responsible for the OTC structure of the federal funds market. Not every loan is of the same quality. The willingness of the lender to expose itself to a particular borrower and a determination of the interest rate on the loan would be awkward to arrange in a typical centralized order-processing market of the sort that normally handles homogeneous assets. Counterparty credit risk could also explain the OTC nature of the market for interest rate swaps, but does not account for the fact that the markets for government and corporate bonds are also OTC.

Two financial institutions can come into contact with each other by various methods in order to negotiate a loan. For example, a federal funds trader at one bank can call a federal funds trader at another bank and ask for quotes. The borrower and lender can also be placed in contact through a broker, although the final amount of a brokered loan is arranged by direct negotiation between the borrowing and lending bank. With our data described in the next section, we are unable to distinguish which loans were brokered. In aggregate, approximately 27 percent of the volume of federal funds loans made during 2005 were brokered. Based on conversations with market experts, we believe that brokerage of loans is less common among the largest banks, which are the focus of our study.

With rare exception, any institution's federal funds balance must be nonnegative at the close of every business day. If necessary, the Discount Window is available as a backstop source of federal funds loans directly from the Fed. Loans through the Discount Window, however, are at an interest rate that is set by fiat at 100 basis points (as of this writing) above the current targeted federal funds rate. The Discount Window rate is therefore highly unattractive to a trader who might have been able to borrow directly from another market participant at rates that are typically negotiated within a few basis points of the target rate. A Discount Window loan, moreover, must be collateralized by acceptable assets that are supplied to the Fed by the borrowing financial institution. This constitutes another incentive to achieve nonnegative balances without using the Discount Window.
A large bank typically targets a rather small, positive balance relative to its total amount sent over Fedwire. Currently, for example, the total amount of reserves held by financial institutions is roughly $\$ 17.3$ billion, whereas the total daily amount sent on Fedwire is over \$2.3 trillion per business day. Banks do not have much incentive to hold reserve balances in large amounts at the close of the business day because these balances do not earn interest from the Fed. Unnecessary end-of-day balances could have been exchanged for interest-bearing overnight assets such as federal funds loans or reverse purchase agreements. During the business day, financial institutions are permitted to have negative balances at a below-market interest rate in their accounts up to a maximum cap. Beyond the caps, these "daylight overdrafts" are charged a penalty fee.

Motivated in part by discussions with federal funds traders, we find that federal funds trading is significantly more sensitive to balances in the last hour of the day. For example, at some large banks, federal funds traders responsible for targeting a small, nonnegative, end-of-day balance ask other profit centers of their banks to avoid large unscheduled transactions (for example currency trades) near the end of the day. Once a federal funds trader has a reasonable estimate of the day's yet-to-be-executed send and receive transactions, he or she can adjust pricing and trading negotiations with other banks to push the bank's balances in the desired direction. We show evidence of this behavior and, further, find that lending is more active when federal funds rate volatility in the trailing half hour is high. James D. Hamilton (1996) discusses the implications of the two-week monitoring cycle for daily price behavior. We do not find evidence of significant dependence of intraday balance targeting on the number of days remaining in the current two-week monitoring period.

We do not consider behavior on days of extreme stress such as the stock market crash of 1987 or on September 11, 2001, when the events at the World Trade Center prevented the Bank of New York from processing payments. Access to the Discount Window and massive infusions of liquidity by the Fed and other central banks would (and did on 9/11) mitigate adverse systemic effects, as explained by James J. McAndrews and Simon M. Potter (2002) and Jeffrey M. Lacker (2004). 


\section{Data}

This study uses transaction-level data from Fedwire. We focus mainly on the top 100 commercial banks by transaction volume and on the business days during 2005. Our dataset permits the construction of real-time balances for each institution, and allows us to identify the sender and receiver of both payments and loans.

We start with payments data documenting every transaction sent over Fedwire during the 251 business days of 2005 . These data include the date, time, amount, and account numbers involved in each transaction. We focus on transactions in the last 90 minutes of the Fedwire business day, between 5:00 p.m. and 6:30 p.m. Eastern time. The large institutions that we study frequently have multiple accounts. We aggregate these accounts by institution, using a mapping from accounts to institutions that is updated every month. We restrict our sample to institutions that are either commercial banks or Government-Sponsored Enterprises (GSEs) such as Freddie Mac, Fannie Mae, and Federal Home Loan Banks, eliminating transactions involving accounts held by central banks, federal or state governments, or other settlement systems. Using these data, we identify the top 100 institutions in each month by the total dollar volume sent, which ranges from less than $\$ 4$ billion to more than $\$ 2$ trillion. The median monthly volume of federal funds sent across the 1,200 institution-months in our sample is $\$ 19.21$ billion. The median across months of the aggregate volume sent is $\$ 12.46$ trillion. Over 80 percent of the institution-months in our sample are for commercial banks, 15 percent are for GSEs, and the remaining 5 percent are for special situations (nonbanks that hold reserve balances at the Federal Reserve). Because our analysis is done at the institution and not the account level, we remove all transactions for which the same institution is the sender and receiver. For purposes of modeling transaction events, we aggregate transactions by date for each senderreceiver pair (of the $9,900=100 \times 100-100$ pairs) for each of the last 90 minutes of the business day. For example, if bank $i$ sends to bank $j$ twice during the minute spanning 5:45 P.M. to 5:46 P.M., we treat this as one event.

We use a dataset developed by the Payments Studies Function at the Federal Reserve Bank of
New York to identify as likely loans those transactions that involve a send in denominations of $\$ 1$ million between a pair of counterparties that is reversed the following business day with plausible federal funds interest. These data are merged with our Fedwire send data in order to separate federal funds loans from nonloan sends. We also use a dataset that documents the balance of each account at the end of every minute in which a transaction occurs. These balances are aggregated across all accounts for each institution, giving us each institution's account balance for each of the last 90 minutes of every business day in our sample. In order to deal with heterogeneity across institutions and time, we normalize each institution's account balance by the following method. From the account balance of institution $i$ at minute $t$ on a particular day, we subtract the median balance for institution $i$ at minute $t$ across all 251 business days of 2005. We then divide this difference by the total amount $V_{i}$ of federal funds sent by this institution over the last 90 minutes of the day in the current month. This normalized balance, denoted $X_{i}(t)$, is a measure of the extent to which institution $i$ has more or less than its normal balance for that minute, relative to the size of the institution (measured by transactions volume).

Among our other explanatory variables are measures of the volatility of the federal funds rate and of the strength of the relationship between pairs of counterparties. In order to capture the volatility of the federal funds rate, we start with a dollar-weighted average during a given minute $t$ of the interest rates of all loans made in that minute. We then measure the time-series sample standard deviation of these minute-by-minute average rates over the previous 30 minutes, denoted $\sigma(t)$. The median federal funds rate volatility is about 3 basis points, but ranges from under 1 basis point to 87 basis points, with a sample standard deviation of 4 basis points. Our measure of sender-receiver relationship strength for a particular pair $(i, j)$ of counterparties, denoted $S_{i j}$, is the dollar volume of transactions sent by $i$ to $j$ over the previous month divided by the dollar volume of all transactions sent by $i$ to the top 100 institutions. The receiver-sender relationship strength $R_{i j}$ is the dollar volume of transactions received by $i$ from $j$ over the previous month divided by the dollar volume of all transactions received by $i$ from 
the top 100 institutions. Because we use a onemonth lagged measure of relationship strength, we do not include transactions from the first month of 2005. These relationship variables are measured on the basis of lending volumes for models of lending probabilities.

\section{Analysis of Transaction Pairing Likelihood}

We begin with an analysis of the determinants of the likelihood $p_{i j}(t)$ of a loan (or of a nonloan send) by institution $i$ to institution $j$ during minute $t$ of a particular business day. We separately analyze loan transactions and nonloan sends. Separate logit models are estimated for each business day. The estimated probability that institution $i$ sends (or lends) to institution $j$ during minute $t$ is modeled with variants of the logit model:

$$
\begin{aligned}
& p_{i j}(t) \\
& \quad=\Lambda\left(V_{i}, V_{j}, X_{i}(t), X_{j}(t), S_{i j}, R_{i j}, \sigma(t), L(t) ; \beta\right),
\end{aligned}
$$

where, for vectors $\boldsymbol{x}$ of covariates and $\boldsymbol{\beta}$ of coefficients, $\Lambda(\boldsymbol{x} ; \boldsymbol{\beta})=e^{\boldsymbol{\beta} \cdot \boldsymbol{x}} /\left(1+e^{\boldsymbol{\beta} \cdot \boldsymbol{x}}\right)$, and, where $L(t)$ is the indicator variable (1 or 0 ), for whether $t$ is after 5:30 P.M. Eastern time.

Detailed maximum likelihood estimates for this and a range of alternative logit models are reported by Aschraft, Duffie, and McAndrews (2007). Here, we describe the general thrust of the results. There are enough data on each business day to identify the coefficients well on most days, and we are reluctant to pool the data across business days because of nonstationarity concerns. The estimated coefficients vary substantially across business days, but are typically statistically significantly different than zero at standard confidence levels. We find a strong relationship between counterparty balances and the probability of a Federal Funds loan. A high balance, relative to normal for that minute, increases the probability of being a lender to a particular potential counterparty. A low balance increases the probability of being a borrower. This relationship tends to be much stronger during the last 60 minutes of the day. The likelihood of a loan is more sensitive to balances than is the likelihood of a nonloan send. For instance, a bank in need of federal funds would be more likely to increase its borrowing than to increase its sales of other assets such as treasuries or currencies.

The probabilities of loans and of nonloan sends decline as the business day comes to a close. Not surprisingly, larger institutions are much more likely to be counterparties on all types of transactions. An increase in funds rate volatility increases the probability of lending and reduces the probability of borrowing, but has little effect on the probability of sending or receiving. Higher funds rate volatility tends to depress lending and sending, although it seems to have a larger impact on the latter. Finally, relationship strength has a significant impact on lending or sending, although this effect is much larger for lending than for sending.

\section{Determinants of the Rate}

We now focus on the determinants of the cross-sectional variation, at a given minute $t$, of the rate $r_{i j}(t)$ negotiated by a particular lender $i$ and borrower $j$, net of the current-minute, dollarweighted average rate $R(t)$ negotiated elsewhere in the market. Our rate data are those for all federal funds loans made between our top 100 institutions during 2005. As explanatory variables, we consider the cross-sectional deciles $d_{i}^{b}$ and $d_{j}^{b}$ of the lender's and borrower's normalized balance $X_{i}(t)$ and $X_{j}(t)$, respectively, relative to the other business days of the year at the same time $t$ of day for the same counterparty. The highest-decile institutions (with $d_{i}^{b}$ $=90$ ) are likely to be among those for which the incentive to lend is greatest, other effects equal. In a centralized market, any market order is assigned the best available price. In an OTC market, however, theory suggests that the price negotiated is increasing in the reservation prices of the buyer and the seller. Our explanatory variable for this effect in the federal funds market is the sum $d_{i}^{b}+d_{j}^{b}$ of the percentile balances of the lender and the borrower. We anticipate that $r_{i j}$ $(t)-R(t)$ decreases, on average, with $d_{i}^{b}+d_{j}^{b}$.

A significant number of loans in our data are made by lenders in the lower deciles by relative balances. Many of these lenders are presumably themselves in relative need of funds but agree to lend at a sufficiently high rate, planning to borrow later in the day at a lower rate. In an OTC market, the borrower does not generally know the most attractive rates available from 
other counterparties, nor which counterparties are offering them, and may have an incentive to accept the rate offered by such a lender. More active institutions are in a better position to offer loans when in need of funds themselves, because they are in a better position to "lay off" their positions later. An analogous effect applies to institutions that are willing to borrow, despite having excess balances. We estimate the impact of these effects on the rate negotiated by including, as an explanatory variable, the difference $d_{i}^{v}-d_{j}^{v}$ between the cross-sectional decile $d_{i}^{v}$ of the lender's transaction volume $V_{i}$, and the corresponding decile $d_{j}^{v}$ of the borrower. By theory, we expect that $r_{i j}(t)-R(t)$ increases on average with $d_{i}^{v}-d_{j}^{v}$.

A basic version of the model to be estimated is

$$
\begin{aligned}
r_{i j}(t)-R(t)= & \alpha+\beta_{1}\left(d_{i}^{b}+d_{j}^{b}\right) \\
& +\beta_{2}\left(d_{i}^{v}-d_{j}^{v}\right) \\
& +\beta_{3} S_{i j}+\beta_{4} R_{i j}+\varepsilon_{i j}(t),
\end{aligned}
$$

where $\varepsilon_{i j}(t)$ is a zero-mean random disturbance that need not be independent across observations. Aschraft, Duffie, and McAndrews (2007) provide least-squares estimates of several variants of this basic model. The standard errors are adjusted for covariances among $\varepsilon_{i j}(t)$ using a conventional panel-regression clustering approach.

The results show that, on average, during the last hour of the day, increasing the balances of the lender and borrower does indeed reduce the loan interest rate that they negotiate relative to rates negotiated elsewhere in the market during the same minute. The rate negotiated is higher for lenders who are more active in the federal funds market relative to the borrower. Likewise, if the borrower is more active in the market than the lender, the rate negotiated is lower, other things equal. This effect is stronger during the last hour of the day. These findings apply after controlling for prior lending relationships between $i$ and $j$ captured by $S_{i j}$ and $R_{i j}$.

In order to account for the ability of institutions to forecast their nonloan sends and receipts for the remainder of the day, Aschraft, Duffie, and McAndrews (2007) explore the implications of replacing current excess balances with a proxy for the conditional expectation at time $t$ of the end-of-day balance of a given institution in the absence of any additional borrowing and lending after time $t$. In order to mitigate concerns that size is a proxy for credit risk, Aschraft, Duffie, and McAndrews (2007) include lender and borrower size deciles as separate regressors and find that most of the impact of size on rate is associated with the lender size, which has no direct bearing on the credit quality of the borrower. $^{1}$

\section{REFERENCES}

Ashcraft, Adam, Darrell Duffie, and James J. McAndrews. 2007. "Over-the-Counter Search Frictions: A Case Study of the Federal Funds Market." Unpublished.

Cocco, João, Francisco Gomes, and Nuno Martins. 2005. "Lending Relationships in the International Market." Unpublished.

-Duffie, Darrell, Nicolae Gârleanu, and Lasse H. Pedersen. 2005. "Over-the-Counter Markets." Econometrica, 73(6): 1815-47.

-Furfine, Craig H. 1999. "The Microstructure of the Federal Funds Market." Financial Markets, Institutions and Instruments, 8(5): 24-44.

-Furfine, Craig H. 2001. "Banks as Monitors of Other Banks: Evidence from the Overnight Federal Funds Market." Journal of Business, 74(1): 33-57.

-Hamilton, James D. 1996. "The Daily Market for Federal Funds." Journal of Political Economy, 104(1): 26-56.

Lacker, Jeffrey M. 2004. "Payment System Disruptions and the Federal Reserve Following September 11, 2001." Journal of Monetary Economics, 51(5): 935-65.

Lagos, Ricardo. 2005. "Asset Prices and Liquidity in an Exchange Economy." Unpublished.

McAndrews, James J., and Simon M. Potter. 2002. "Liquidity Effects of the Events of September 11, 2001." Federal Reserve Bank of New York Economic Policy Review, 8(2): 59-79.

Vayanos, Dimitri, and Pierre-Olivier Weill. 2005. "A Search-Based Theory of the On-the-Run Phenomenon." Unpublished.

\footnotetext{
${ }^{1}$ For empirical models of how credit quality affects interbank loan rates, see João Cocco, Francisco Gomes, and Nuno Martins (2005) and Furfine (2001).
} 
This article has been cited by:

1. Craig H. Furfine. 2011. Comment on: "The Mechanics of a Graceful Exit". Journal of Monetary Economics . [CrossRef]

2. Jahangir Sultan. 2011. Options on federal funds futures and interest rate volatility. Journal of Futures Markets n/a. [CrossRef] 